\title{
GEMSTONE CARVING IN CHINA: WINDS OF CHANGE
}

\author{
By Sally A. Thomas and Hing Wa Lee
}

The Chinese have labored to perfect the art of gemstone carving for several thousand years. Beginning with primitive tools and limited materials, they eventually developed the iron-tipped spindles and treadle machines that were to become the traditional tools of the trade for two millenia. With these relatively simple implements and meticulous craftsmanship, Chinese master carvers have produced some of the world's most sophisticated gemstone carvings. Within the past 10 years, however, increased governmental participation, the availability of powerdriven machinery, and more varied carving materials have had a major impact on gemstone carving in China.

\footnotetext{
ABOUT THE AUTHORS

Ms. Thomas is a writer and editor at the Gemological Institute of America in Santa Monica, California. Mr. Lee is a master gemstone carver and owner of H.W. Lee Gallery in Los Angeles, California

Acknowledgments: The authors would like to thank Judy Greene, Miriam Lytle, and John Lizzadro, of the Lizzadro Museum of Lapidary Art in Elmhurst, Illinois, for allowing us to reproduce some of their photos. Thanks also go to Harold and Erica Van Pelt of Los Angeles for their photographic contributions.

(C1986 Gemological Institute of America
}

\begin{abstract}
Cemstone carving is one of China's most ancient and Iimportant art forms. It is a craft steeped in history and tradition, continually reflecting the philosophy and culture of the Chinese people. Using primitive tools and native nephrite, early Chinese carvers created crude tools and weapons. Over the course of several thousand years, however, master craftsmen worked to perfect the tools and techniques that would help them create smooth, flowing carvings from intractable blocks of stone. Using only simple foot-driven machines and iron-tipped spindles, as many as 50 carvers might labor more than 10 years to complete a single masterpiece (figure 1).

Through generations of traditional training-long apprenticeships with masters in the art-Chinese carvers became extremely talented at adapting their designs to the patterns, colors, and imperfections within each stone. The result of such skill is particularly evident in those pieces that depict many differently colored figures, all carved from the same piece of rough (figure 2). The art of gemstone carving reached its zenith during the reign of Emperor Ch'ien Lung (1736-1795). Dedicated to the advancement and perfection of all the arts, Ch'ien Lung established several imperial workshops in Peking (now Beijing) which produced some of the finest carvings ever created. Surviving specimens of these magnificent carvings can be seen today in the Forbidden City Museum in Beijing.

After Ch'ien Lung's abdication in 1795, China plunged into political turmoil and cultural darkness that dominated the 19 th and early 20 th centuries. Only within the last 50 years has gemstone carving experienced a major revival. During the past 10 years, in particular, increased governmental participation, the introduction of modern, power-driven tools, and access to a greater variety of carving materials has changed the gemstone-carving industry in China.
\end{abstract}




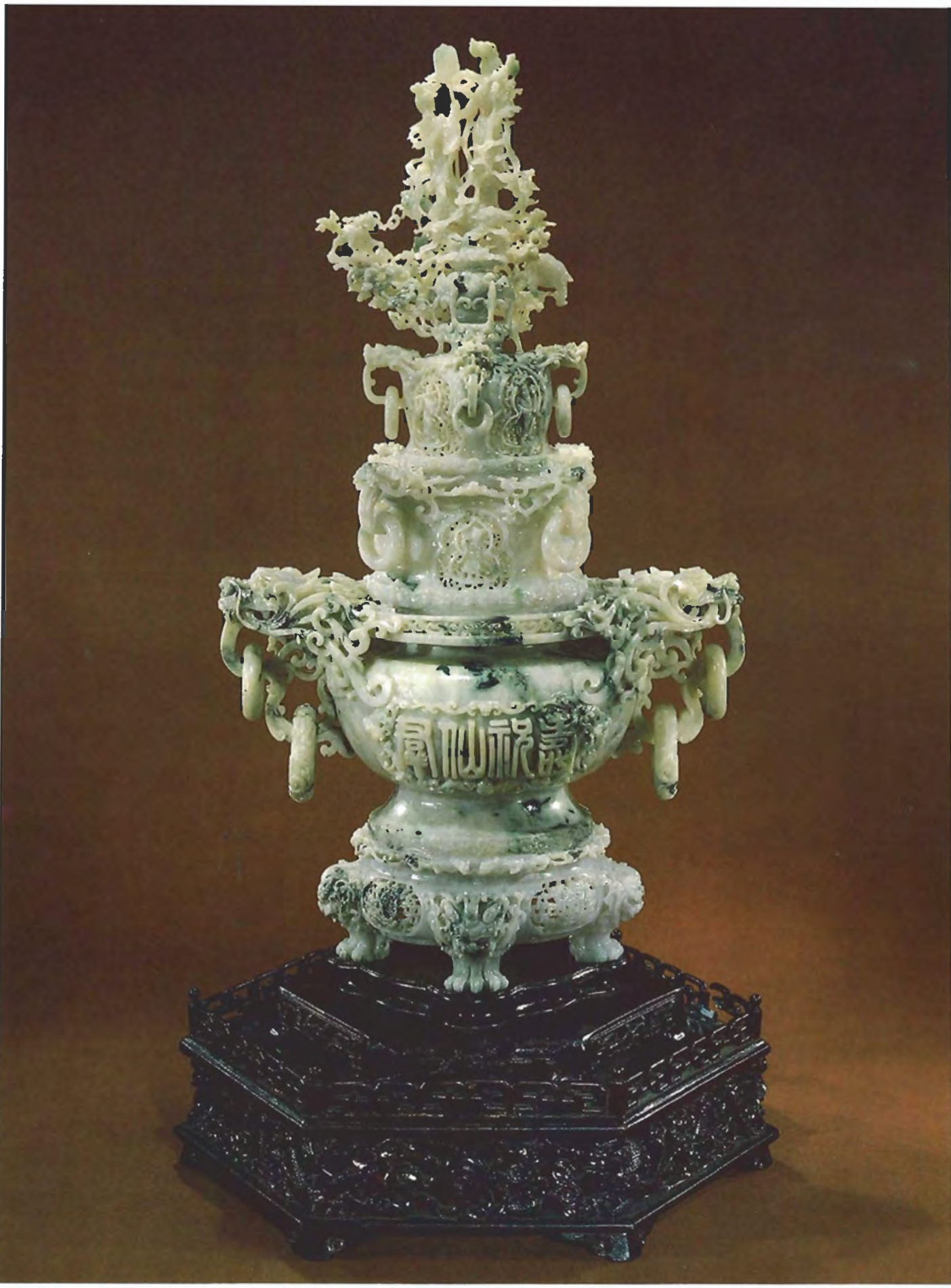

Figure 1. This intricately designed jadeite incense burner was carved almost 200 years ago. It measures 68 $\mathrm{cm}$ tall $\times 40 \mathrm{~cm}$ wide, and may have taken as many as 10 years to complete.

Courtesy of H.W. Lee Gallery; photo (C Harold es) Erica Van Pelt.

\section{EARLY HISTORY}

The glyptic arts have ancient roots dating back to Paleolithic man, who first made crude carvings using bits of hard rocks for tools. As man's technology progressed, so did his ability to carve stones. Ancient carvers in China first used a thin, sharp sliver of sandstone sluiced with wet sand as a primitive saw for large pieces of rough stone. Next they used a bow drill, a tool common to many early cultures (Long, 1982). This drill consisted of a simple, flexible wooden bow braced with a bowstring. Snared in the middle of the taut bowstring was a thin wooden shaft that had a sharp drill point at one end and a handle or a mouth brace at the other. By sawing the bow back and forth, the pointed shaft rotated very quickly, the friction drilling a hole into the stone beneath the point. Although it was a vast improvement over chip- 


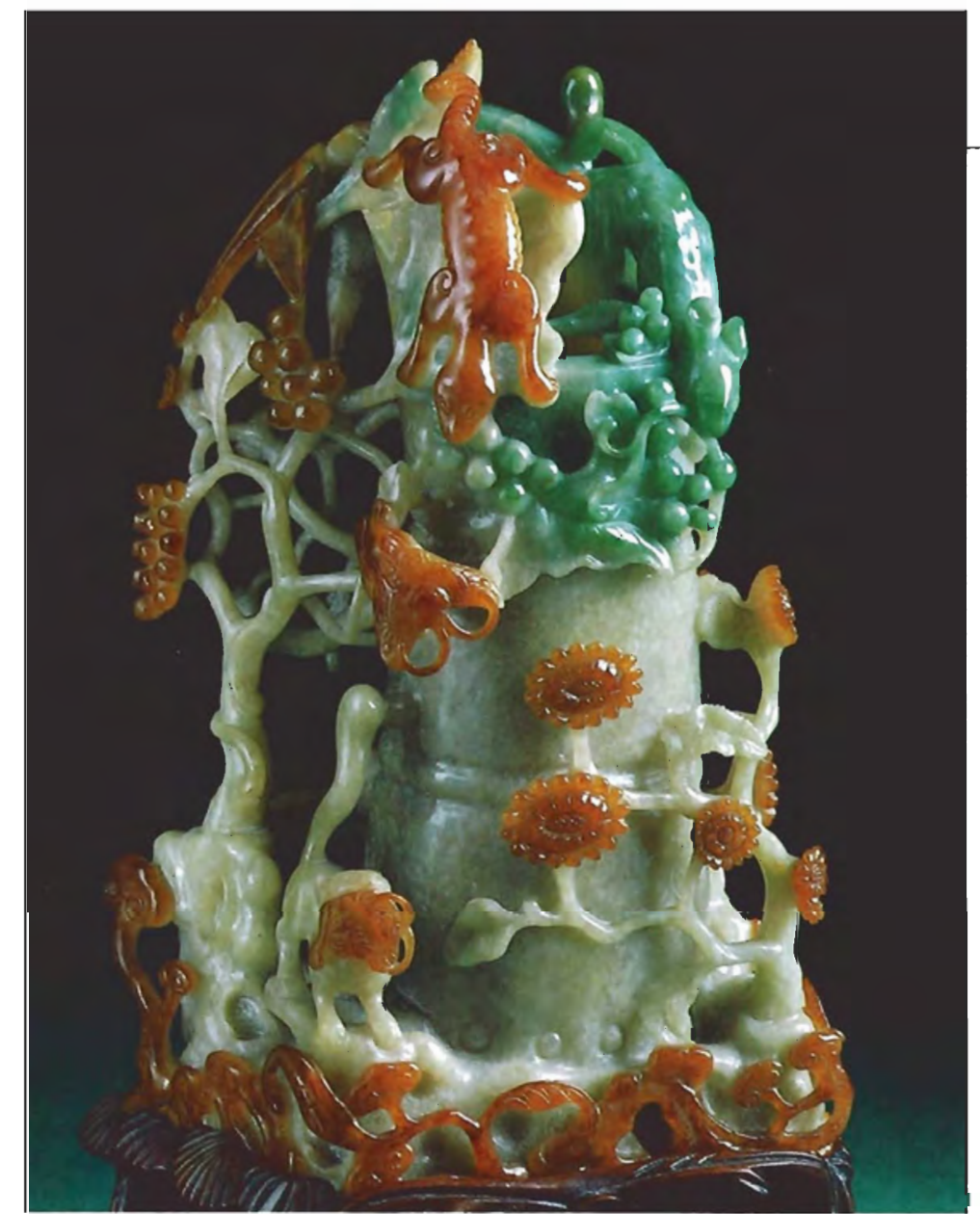

Figure 2. This jadeite vase $(14 \times 8 \mathrm{~cm})$ demonstrates how skillful Chinese craftsmen have utilized the bright orange rind, a brownish green core, and a patch of emerald green on a single piece of iade. Reproduced courtesy of the Lizzadro Museum of Lapidary Art.

ping, only very basic carvings could be fashioned with this tool. The Chinese eventually employed tubular drills made of bamboo (Long, 1982). Because bamboo is porous, abrasive grit clings to its cross section, making the bamboo shaft a more effective, if still tedious, drilling tool.

Although China contains large deposits of quartz, primarily from the provinces of Hunan and Hubei, and Chinese carvers have produced a great number of quartz carvings over the centuries (figure 3), the primary carving stone for China historically has been jade (Lytle, 1982). Jade-specifically nephrite jade until jadeite was first imported from Burma in the late 18th century-is uniquely bonded to Chinese culture, tradition, and aesthetics (Tucker, 1982). Chinese carvers first prized nephrite for its toughness, relative ease of sawing and drilling, and variety of color. Ancient nephrite deposits were located in the Khotan and Yarkand regions, and later in Yunnan Province and the interior of Turkestan (Hansford, 1950).

Nephrite was renowned for its durability, and many of the uninitiated were skeptical that such a stone could be cut and carved. Some ancient Chinese writers even believed that jade must have been a soft material when it was initially removed from the earth, and that it hardened only after exposure to the elements. Others believed that jade could be softened for carving by smearing it with a grease extracted from a rare species of toad (Long, 1982).

\section{THE METAL ERA}

Although bronze certainly played a pivotal role in the advancement of Chinese technology and culture, there is no evidence that it was used in gemstone carving (Long, 1982). Iron was first introduced into China around 500 B.C., about the time that word of the K'un-wu, or "sword-knife," began to spread throughout China (Hansford, 1950). Popular legend had it that this knife was made from a material that was so strong it could cut through jade as though it were clay. Although evidence to establish the existence of such a knife is lacking, it is interesting to note that the name K'un-wu corresponds to a tribe of people in a region to the northwest of ancient China that was an ancient source of iron ore (Howard, 1950).

The advent of iron and metal alloys revolutionized Chinese lapidary work. Stone carvers eventually developed a metal saw that could cut its way through the largest nephrite boulders. A length of iron wire was doubled and twisted to form a blade, which was stretched between the ends of a large wooden bow. Two men held opposite ends and sawed the wire across the stone, while a third person fed a slurry of abrasive grit and water into the groove where the wire entered the stone. Although it was a slow process, it enabled very large pieces to be sectioned off with very little loss of material.

During this period, the Chinese invented the rotary foot-treadle carving machine that would be used for centuries to come, up to and including the present day (figure 4). This machine consists of a simple wooden bench with two foot treadles attached to a leather thong. Iron-tipped wooden spindles of various shapes and sizes can be attached horizontally to a wooden holder. Then the leather thong is looped over the spindle. When the foot treadles are pumped vigorously, they cause 
the iron-tipped spindles to rotate rapidly back and forth; the carver then presses the stone against the metal tip to carve out a pattern. The tips range from large metal discs, or circular saws, up to a foot in diameter down to the extremely small points used for engraving (figure 5). Bow drills can also be used with the treadle machine. The real merit of the treadle machine is that very slow speeds can be used to start cuts or finish delicate designs, and that resistance or other "feedback" can be felt in the hands of the carver or in the pedals (figure 6).

To keep the stone cool and damp, early Chinese carvers used an abrasive mud or sand composed of grains of quartzite, garnet, and corundum. Diamond was sometimes used as a point for a drilling tool even before the Christian era (Hansford, 1950), but not as an abrasive.

The development of the foot treadle allowed the carver a great amount of control while shaping the piece. The skill needed to operate the machine as adeptly as possible was not easy to learn, and apprenticeships could last as long as 10 years. The carving process itself was extremely slow and tedious, and many carvers received deep cuts and slashes when their fingers or hands came too close to the whirling iron tools after many hours on the bench. But with skill, patience, and luck, a master carver could produce an intricate piece that would be treasured for generations to come.

The Chinese have followed the same basic carving procedures for many centuries. First they decrust and cut open the main jade boulder. Next they examine the stone closely, noting all flaws, patterns, and color variations, and then they design their carving accordingly. The unwanted pieces are sawed away, and the pattern is carefully drawn on the stone with ink. Then comes the long carving process, using a variety of tubes, drills, round gouges, and reamers. The last step is a painstaking polishing. Nephrite is somewhat difficult to polish, and special care must be taken to achieve the finest possible finish. Early polishing tools were made of fine-grained wood covered with dried gourd skin and ox leather charged with ruby dust (Bushell, 1914).

\section{THE GOLDEN ERA}

Over the centuries, gemstone carving became a very intricate art form. The best carvings were produced during the Sung (960-1280), Ming (1368-1644), and early to mid Ch'ing (1644-1912) dynasties. It was during the reign of Emperor
Ch'ien Lung (1736-1795), in particular, that the art of gemstone carving reached the height of sophistication and beauty (Burwell, 1948). Ch'ien Lung established several workshops at the imperial palace in Beijing which were devoted to this art. He also imported skilled Moslem gem carvers from the province of Sinkiang, men who could trace their skills back to the ancient cities of Chaldea and Susiana at the head of the Persian Gulf (Bushell, 1914). Moghul carvings were typi-

Figure 3. China has also been known for its beautiful rock crystal quartz carvings, such as this undercut ornamental bottle $(27 \times 12 \times 10$ $\mathrm{cm})$. The butterflies, birds, blossoms, fruit, and cicadas collectively symbolize the summer solstice. Reproduced courtesy of the Lizzadro Museum of Lapidary Art. 


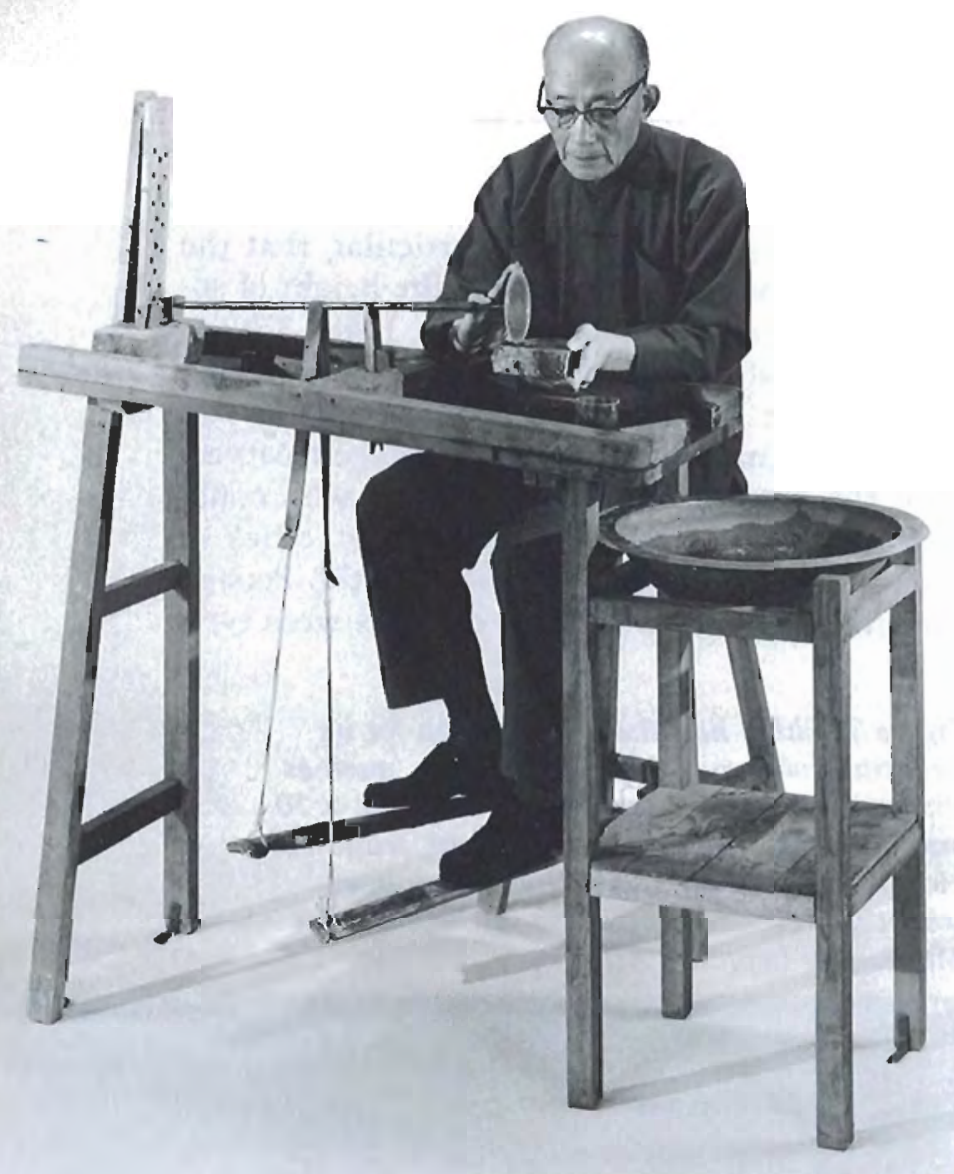

Figure 4. For two millenia, fine gemstone carvings have been created by master carvers such as $T$. $C$. Chang using this type of foot-treadle machine. Photo (C) Harold ed Erica Van Pelt.

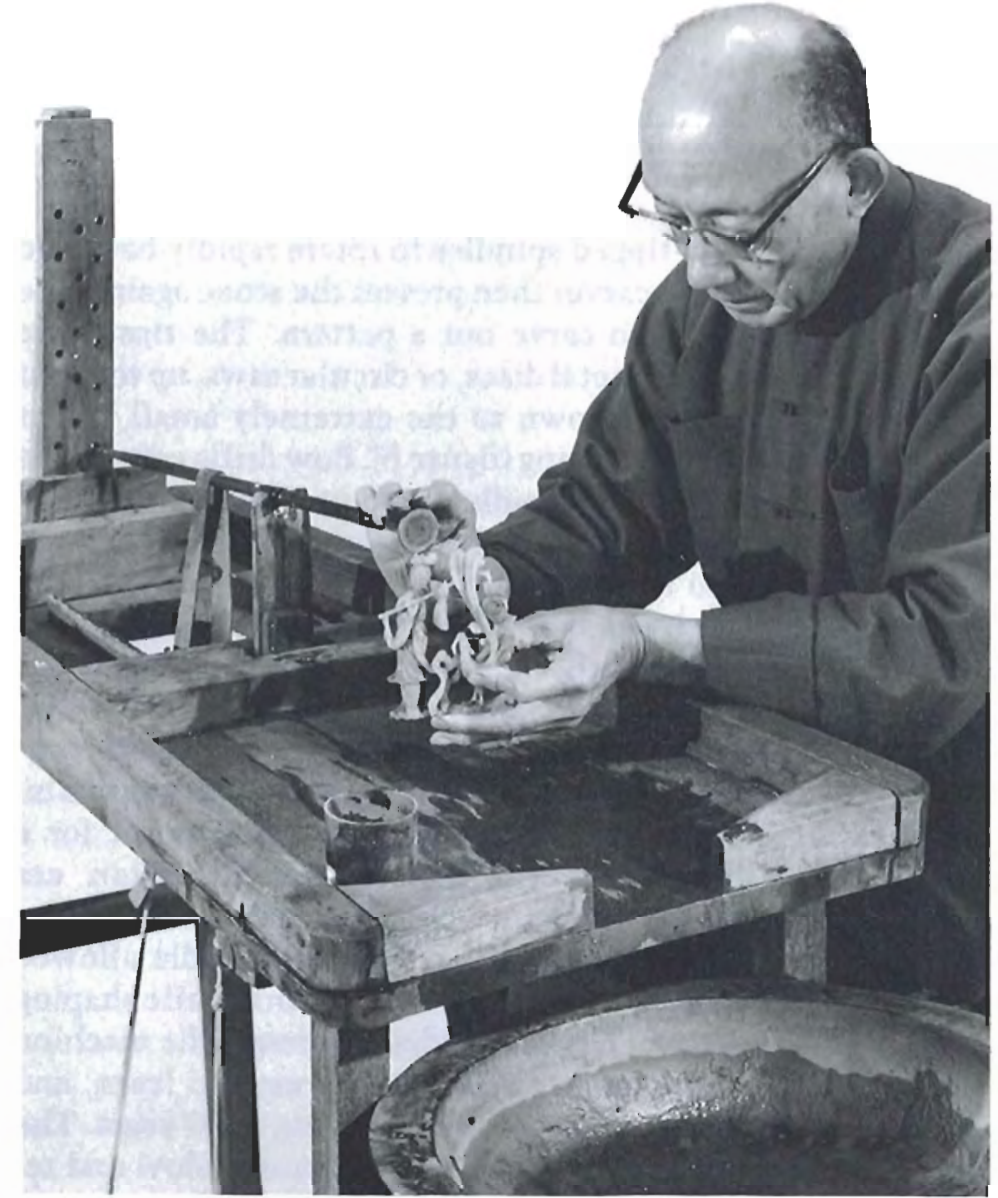

Figure 6. Through feedback from the pedals and his hands, the carver can exercise the control necessary to produce delicate carvings. Photo (C) Harold $\Theta$ Erica Van Pelt.
Figure 5. These tools of the Chinese master carver are used in conjunction with the treadle machine shown in figure 4. Photo (C) Harold \&) Erica Van Pelt.

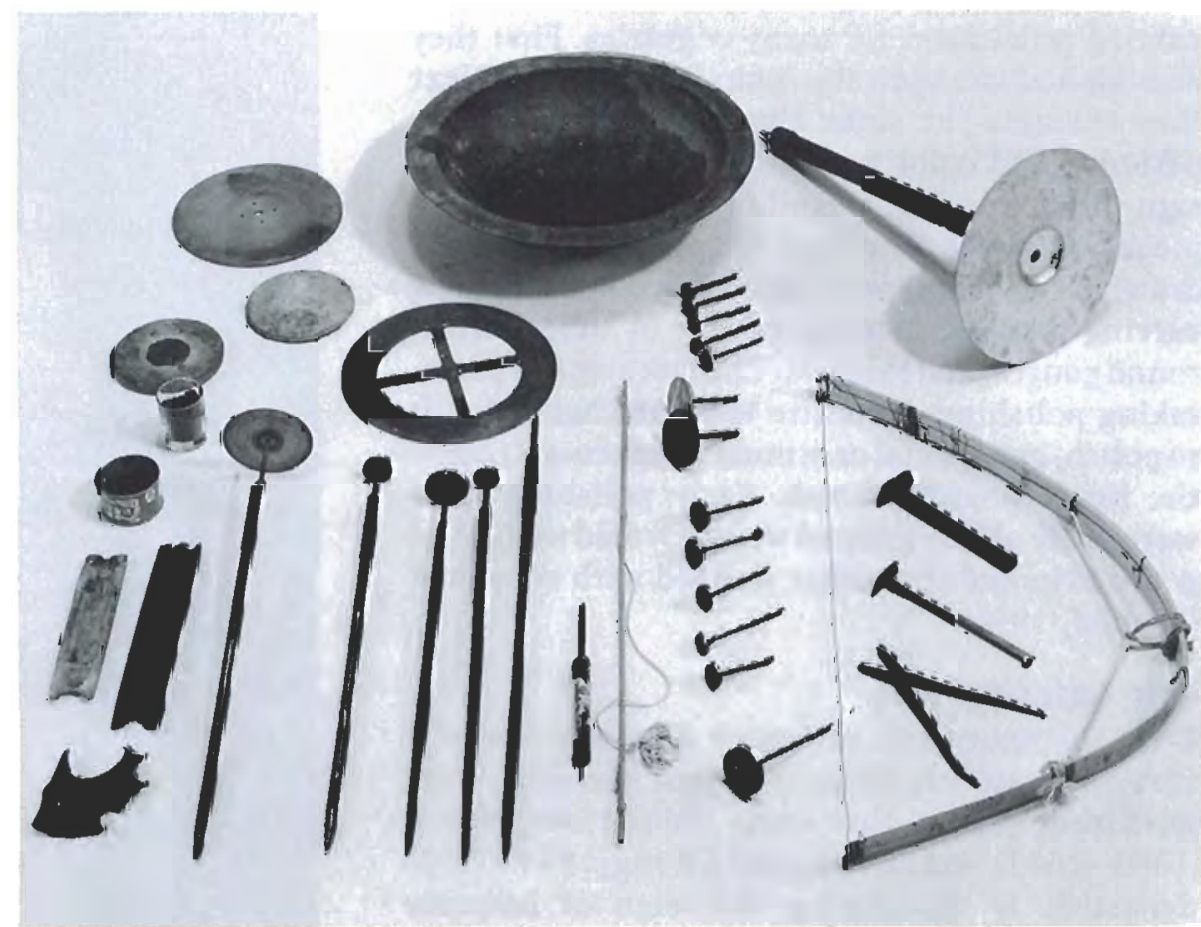


cally finely detailed and skillfully executed; the sides of many fine Moghul carvings are so thin that the stone appears to be translucent (figure 7).

One of the imperial workshops was called $H s i$ Fan Tso, or "Indian School," and produced graceful, delicate carvings reminiscent of the style then popular in India (Bushell, 1914). It is also probable that the jeweled jades from this period were inspired by this same source. These pieces were usually flat plates carved from white jade and mounted in small screens. They were inlaid with rubies, amethysts, lapis lazuli, and emerald-green jadeite, cut in thin slices or set en cabochon and etched with golden lines.

In 1784, China opened up trade relations with Burma and began to import large quantities of various colors of jadeite, including lavender and the rarer blue, as well as white and the various shades of green (Lytle, 1982). Because jadeite fractures more easily than nephrite, carvers were initially reluctant to work with this new material (Long, 1982). Through experimentation, however, they soon learned to adapt their techniques, and in turn produced magnificent carvings from the sometimes multicolored jadeite (see cover).

\section{MAJOR MOTIFS}

Although the subjects of the carvings have varied throughout history, most reflect the basic Eastern philosophy that man is only a small part of a greater scheme (Tucker, 1982). The Chinese artisans sought to emulate nature by observing its way, and thus became highly skilled at capturing the spirit of nature within their carvings. Taoism, the oldest extant religion in China, is a form of nature worship, and helped to imbue animals, insects, trees, and flowers with their own special symbolism. For example, bats symbolize happiness and the metamorphosis between heaven and earth. Fish represent wealth, abundance, and marital bliss. A fox is associated with evil spirits. The pine tree is believed to contain an abundance of vital energy and therefore represents long life and immortality. Interestingly, cats are believed to be capable of both creating and dispelling evil (Lytle, 1982). Other, mythical creatures, such as the phoenix, the dragon, and the Qilin (an amalgamation of all creatures), have all been important motifs in Chinese carving.

The types of items that are carved include ornate incense burners, vases, covered jars, bowls, wine holders, and snuff bottles, as well as orna-

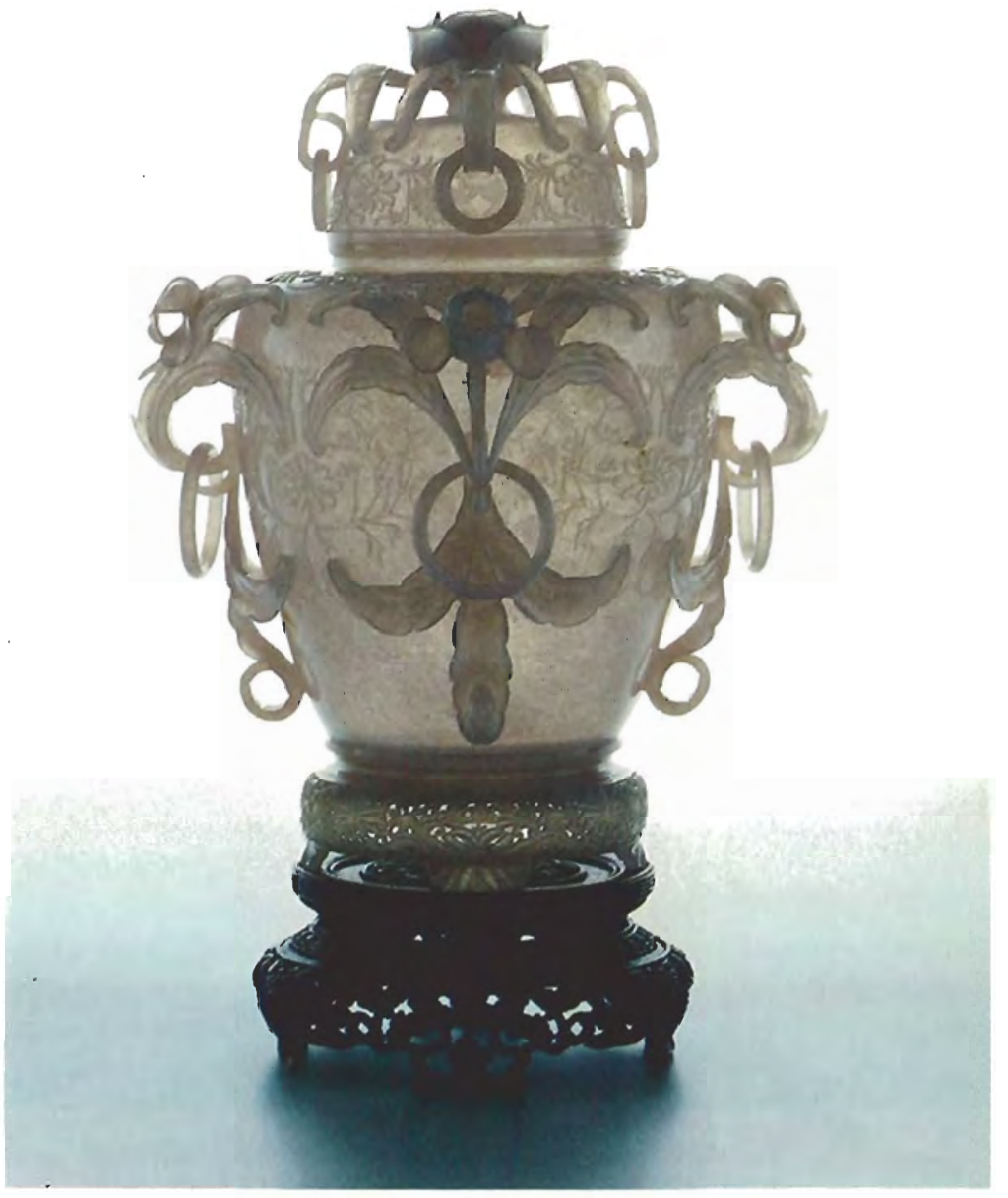

Figure 7. This white nephrite vase $(27 \times 15 \times 7 \mathrm{~cm})$ displays the skill that is so evident in Moghul carvings. The walls of this piece are only onesixteenth of an inch thick. Reproduced courtesy of the Lizzadro Museum of Lapidary Art.

ments for clothing and special objets. Buddhism has historically been one of China's major religions, and its influence can be seen in many figurines. Boulder carvings were especially popular during the mid- to late 18th century. Carved from a solid boulder of jade, these pieces often depicted a Buddhist monk inside an austere cave, an appropriate setting for those dedicated to the contemplative life (Lytle, 1982; Tucker, 1982).

In addition to the larger carvings, many smaller pieces are produced. Expert craftsmen carved tiny bottles-most only $1^{1 / 2}$ in. (about $4 \mathrm{~cm}$ ) high-to hold a nobleperson's precious supply of snuff, a powdered form of tobacco mixed with pungent herbs (Perry, 1960). These miniature bottles with their tight-fitting lids were fashioned from almost every gem material, including chalcedony, amethyst, quartz, and even ruby and emerald (Thomas, 1986). Jade was especially popular, since 
predecessor. Almost fanatically repelled by the corruption and waste that he associated with the arts, he started China's plunge into cultural darkness. The great imperial workshops in Beijing were disbanded, and carvers were left to pursue their craft as best they could.

China's turmoil grew worse as the country became entangled in both foreign and domestic upheaval. During the next century, China's imperial houses, and even imperial rule itself, collapsed. Few documented accounts of gemstone carving during that time have been found. Almost one hundred years after Chia Ch'ing's death, however, Stephen Bushell reported in 1914 that the traditional treadle machines and carving methods were still in use, and noted that carvers were working with more rock crystal, carnelian, sardonyx, onyx, and agate. At that time, carvers in Beijing were using special types of abrasives, in increasing power: (1) yellow sand (quartz crystals), (2) red sand (garnets) used with the circular saw, (3) a kind of emery (black corundum sand) used with lap wheels, and (4) "jewel dust" (ruby crystals) from Yunnan and Tibet smeared onto the leather polishing wheel.

From 1920 to 1940, a quantity of fine, applegreen Siberian nephrite known as Liu's Jade (figure 9) appeared in Beijing (Lytle, 1982). This unusual jade had been stored in the Imperial Russian Treasury until the Communist takeover, when it was confiscated and shipped to Beijing to raise revenue. The quality of both the jade and the carvings created from it is generally very fine. Interestingly, most of the carvings made from this material bear the seal of Emperor Ch'ien Lung on their bases, although it is certain that Liu's Jade was not introduced into China until 1920, 125 years after that emperor's abdication.

In the years preceding World War II, Beijing again became active in the gemstone-carving industry, particularly in jade. Hansford (1950) reported that several hundred craftsmen and apprentices were employed in that city during those years. Many fine vessels and figurines were being produced there, and antique carvings were also available. Other carving centers were established in Canton and Shanghai, which mainly produced jadeite jewelry. The size of the workshops varied greatly, and many specialized in carving one particular stone or one particular item. Certain elaborate items that had previously been commissioned by the royal family, such as objects with long inscriptions and huge "mountains" complete with

Tragically, China's next emperor, Chia Ch'ing (1796-1820) proved to be the antithesis of his 


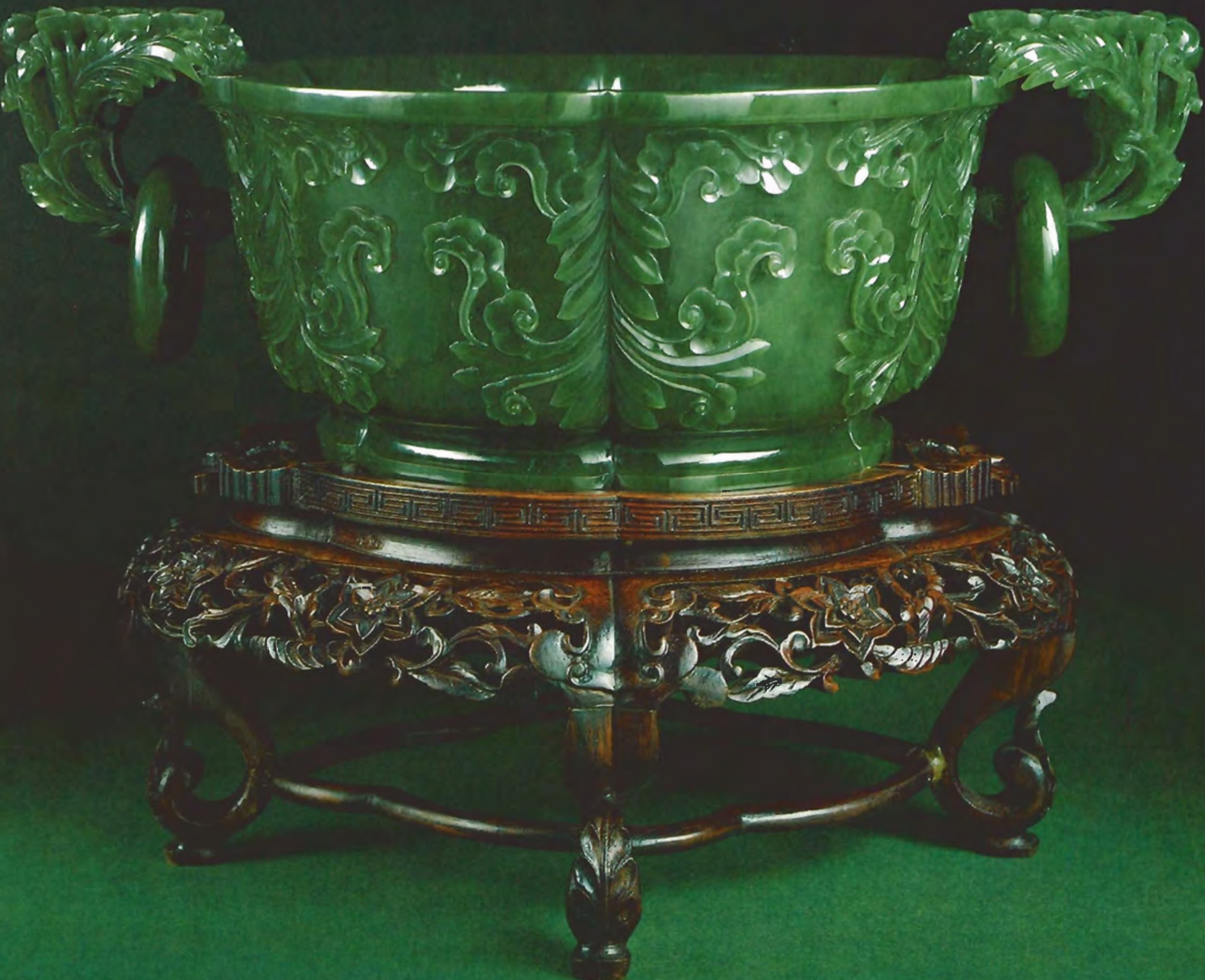

Figure 9. Known as Liu's Jade, this deep apple-green nephrite $(11 \times 30 \times 20 \mathrm{~cm})$ was popular during the 1920 s and 1930s. This bowl was carved in a style that was common in the mid-Ch'ing Dynasty. Reproduced courtesy of the Lizzadro Museum of Lapidary Art.

figurines, groves, and pavilions, were no longer being carved because there was no market for such ornate-and expensive-pieces.

In 1948, Calvin Joiner reported on a special area of Beijing called Jade Street, located just outside the Ch'ien gateway. Stretching for half a mile, it was lined with tiny shops that featured a fantastic variety of carvings. Behind the shops were carv- ing workshops, many of which were occupied by descendants of the Moslems who had been brought to Beijing by Emperor Ch'ien Lung. According to Joiner, carvers were still using the traditional machines and methods, but had instituted a production-line type of carving whereby the workmen and beginning apprentices did the heavy slicing, the more advanced apprentices did the 
rough carving, and the final detail was accomplished by the master carvers, who also completed the polishing.

\section{REVOLUTION}

The Communist Revolution that occurred in China during 1949-50 brought a great many economic reforms (Langer, 1972). Overall state planning in industry, including gemstone carving, was instituted during this period.

With time, however, factions developed within the government as many of the new leaders felt that China was leaning too far toward capitalism. The antagonism came to a head in 1965, when China was shaken by the Great Proletarian Cultural Revolution. Three years later, the revolution was officially at an end, but its effects interrupted the country's economic and industrial progress for several more years; China was essentially closed to all foreigners for almost 10 years. Gradually, under the leadership of Lin Piao (Mao's successor), the giant country began to open its doors to the Western world.

\section{MODERN CHINESE GEM CARVING}

Within the last 10 years, the gemstone-carving industry in China has undergone several major changes (Markbreiter, 1985). Most notable is a marked increase in governmental participation and control. Virtually all major carving is now accomplished at government-owned factories, which also supply the carvers with all rough material. The new factories employ anywhere from

Figure 10. Modern Chinese power-driven carving machinery now uses diamond-impregnated tips instead of the traditional powdered abrasives.

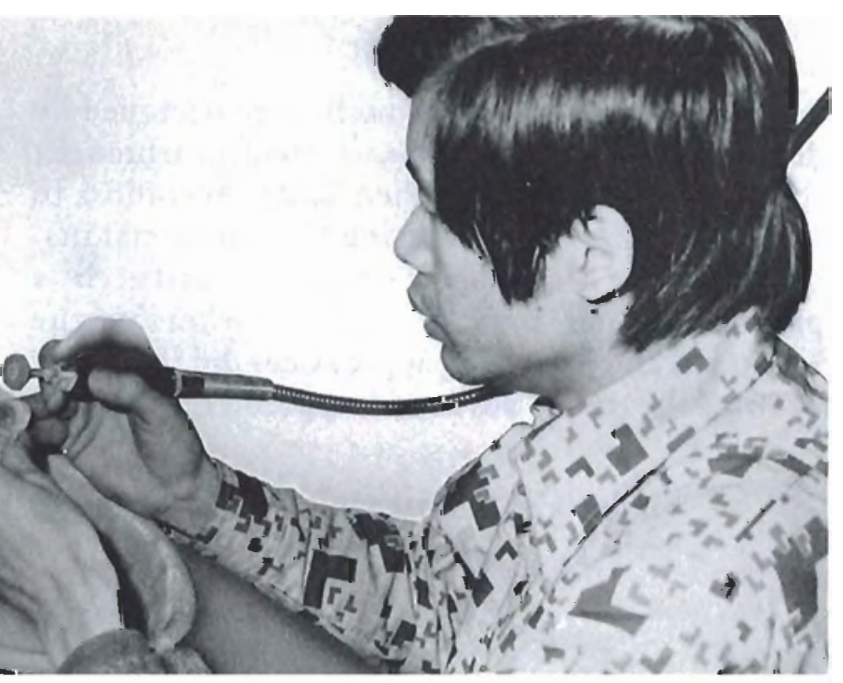

20 to 10,000 people, and both men and women may learn the craft. The factories appear to be well lighted and ventilated, with rows of machines for the workers. The government is very interested in the success of this particular industry, and is offering tax incentives and other benefits to encourage Taiwanese gemstone carvers to both carve and teach their craft on the mainland (Tucker, 1982).

Perhaps one of the biggest changes in the industry is the introduction of power-driven machinery (figure 10). About a decade ago, the Chinese began to import modern electric tools from Europe. More recently, they have begun manufacturing their own machinery and tools (Read, 1981; Markbreiter, 1985). Most of these machines are high-speed saws, and drills similar to those used by a dentist. Instead of the powdered abrasives used in the past, the carving tools are now impregnated with diamond dust or corundum. Water is supplied from thin rubber tubes installed above the machinery. Diamond dust is also used in the polishing process, and produces a glossier finish than do the traditional abrasives.

Power-driven tools have played a major role in changing the carving industry. Large, intricate pieces can now be completed in a fraction of the time that was needed only a few years ago. The period of apprenticeship has dropped to about four years, and may now require successful completion of examinations (Markbreiter, 1985). The new carvers are now being taught a mixture of old and new methods. Although they use the new, powerdriven machinery, the traditional carving steps are still basically the same. As in the past, several people of ten work on a single piece. For example, an apprentice may do a rough preform from the design the master has drawn on the stone, but then "specialists" may be brought in to do various aspects of the detail work. Faces and hands are particularly difficult and may be assigned to one person with well-developed expertise in carving such delicate areas. Often, the master does the final detail work and finishes polishing the piece.

Although the new machines and tools can produce a greater quantity of delicate relief work in far less time, they do have drawbacks. The new diamond-impregnated saws waste from 2 to $5 \mathrm{~mm}$ more of the material, an important consideration when carving gem-quality rough. In addition, the rapidly rotating saws and drills do not offer the instant control of foot-driven treadles, and costly mistakes can occur in a fraction of a second. Con- 
cantly from their predecessors. However, some factories are diversifying. For example, in one large establishment in Canton, one division produces "largely unoriginal and highly commercial" work, while another division creates the larger, betterquality carvings (Markbreiter, 1985).

Beads, pendants, and other items of jewelry are among the most common objects carved, although statues, vases, and other large items continue to be popular (figure 11). In addition to nephrite from Xinjian Province and jadeite from Burma / the Chinese government is the single largest purchaser of jadeite), the materials used most often include lapis lazuli from Afghanistan, rose quartz from Brazil and Africa, and ivory from Africa, as well as native turquoise, agate, fluorite, serpentine, soapstone and other "jade-like" materials (frequently, in China, any opaque ornamental material is referred to as "jade" $)$. On rare occasions, carvings are made from gem materials such as tourmaline, amethyst, and aquamarine, in most cases using imported material. Carved opal is also seen occasionally.

\section{MARKETING AND DISTRIBUTION}

The China National Arts and Crafts Corporation in Beijing presently controls the distribution of all finished carvings. Most pieces are sold locally to tourists through the Friendship Stores / where only foreigners can make purchases, using a special currency required of foreigners and not allowed to Chinese citizens) and smaller state-owned "antique" or "jade" shops found in most of the major cities of China, or are exported, primarily to Japan and Hong Kong. Tens of thousands of carved pieces of jewelry and other items are now exported every year.

\section{CONCLUSION}

Despite the growing trend toward the use of power-driven machinery in carving, there are still a few masters who remain faithful to the traditional treadle machines and tools. In 1963, Mr. T. C. Chang (again, see figure 4), a Hong Kong gem carver and former head of the Beijing Jade Craftsman Union, was commissioned to recreate from memory two vases that he had seen as a boy. When asked why he preferred to use the traditional foot treadle for this delicate project, he replied:

"The old tools are best because they permit you to use your whole body,

Feet to regulate the cutter,

Ears to hear the stone as it is cut,

Hands to hold it,

Eyes and Heart to seek out and hold the design in the stone. ${ }^{\prime *}$

Modern machinery has made the commercial Chinese gemstone carving industry roughly equal in quality to those in Hong Kong and Taiwan. Nevertheless, the larger fine pieces, comparable to those created during the 18 th century, are still being created by a few, dedicated Chinese master craftsmen.

*Lytle, 1982.

\section{REFERENCES}

Burwell W.B. (1948) Exhibition of Chinese jades-OACLondon. Oriental Art, Autumn, p. 157.

Bushel S.W. (1914) Chinese Art, Vol. 1, 2nd ed. Victoria and Albert Museum, London.

Hansford S.H. (1950) Chinese Jade Carving. Lund Humphries Co., London.

Joyner C. (1948) Behind the scenes in Jade Street. Gems $\Theta$ Gemology, Vol. 16, No. 3, pp. 82-86.

Langer W. (1972) An Encyclopedia of World History, 5th ed. Houghton Mifflin Co., Boston, MA.

Long F.W. (1982) Lapidary Carving. Van Nostrand Reinhold Co., NY.
Lytle M. (1982) The Lizzadro Collection. John Racila Associ ates, Oak Brook, IL.

Markbreiter S. (1985) Jade carving in two cities. Arts of Asia, Vol. 15, No. 1, pp. 63-73.

Perry L. (1960) Chinese Snuff Bottles: The Adventures and Studies of a Collector. Charles E. Tuttle Co., Rutland, VT.

Read P. (1981) Travels in China. Canadian leweller, June, pp. 134,135 , and 137.

Thomas S. (1986) Snuff bottles: nothing to sneeze at. In Focus, Winter, pp. 12-14.

Tucker E. (1982) Jade forms from ancient China. Gems of Gemology, Vol. 18, No. 1, pp. 20-31. 